\title{
Effects of Football Training and Match-Play on Hamstring Muscle Strength and Passive Hip and Ankle Range of Motion during the Competitive Season
}

\author{
Víctor Moreno-Pérez $^{1}{ }^{(\mathbb{D}}$, Gil Rodas $^{2}$ (D), Marcelo Peñaranda-Moraga ${ }^{3}$, Álvaro López-Samanes ${ }^{4}$ (D), \\ Daniel Romero-Rodríguez ${ }^{5}$, Per Aagaard ${ }^{6}$ and Juan Del Coso ${ }^{7, *(\mathbb{D})}$
}

Citation: Moreno-Pérez, V.; Rodas,

G.; Peñaranda-Moraga, M.;

López-Samanes, Á.;

Romero-Rodríguez, D.; Aagaard, P. Del Coso, J. Effects of Football Training and Match-Play on Hamstring Muscle Strength and Passive Hip and Ankle Range of Motion during the Competitive Season. Int. J. Environ. Res. Public Health 2022, 19, 2897. https:// doi.org/10.3390/ijerph19052897

Academic Editors: Hugo Miguel Borges Sarmento, Tomás Garcia-Calvo, Filipe Manuel Clemente and Adilson Marques

Received: 14 January 2022 Accepted: 28 February 2022 Published: 2 March 2022

Publisher's Note: MDPI stays neutral with regard to jurisdictional claims in published maps and institutional affiliations.

Copyright: (C) 2022 by the authors. Licensee MDPI, Basel, Switzerland. This article is an open access article distributed under the terms and conditions of the Creative Commons Attribution (CC BY) license (https:// creativecommons.org/licenses/by/ $4.0 /)$.

\footnotetext{
Sports Research Centre, Miguel Hernandez University of Elche, 03202 Elche, Spain; vmoreno@umh.es 2 Medical Department, Futbol Club Barcelona, 08028 Barcelona, Spain; gil.rodas@fcbarcelona.cat 3 Elche Football Club SAD, 03208 Elche, Spain; david.penaranda@goumh.umh.es

4 Faculty of Health Sciences, Universidad Francisco de Vitoria, 28223 Pozuelo de Alarcón, Spain; alvaro.lopez@ufv.es

5 Sport Performance Area, Futbol Club Barcelona, 08028 Barcelona, Spain; danirrphysco@gmail.com

6 Department of Sports Science and Clinical Biomechanics, Research Unit for Muscle Physiology and Biomechanics, University of Southern Denmark, 5230 Odense, Denmark; paagaard@health.sdu.dk

7 Centre for Sport Studies, Rey Juan Carlos University, 28943 Fuenlabrada, Spain

* Correspondence: juan.delcoso@urjc.es
}

\begin{abstract}
Deficits in hamstring muscle strength and in hip range of motion (ROM) have been considered risk factors for hamstring muscle injuries. However, there is a lack of information on how chronic exposure to regular football training affects hamstring muscle strength and hip ROM. The aim of this study was to examine the longitudinal effect of football training and competition during a complete season on hamstring muscle strength and hip ROM in football players. A total of 26 semi-professional football players underwent measurements of isometric hamstring muscle strength and passive hip flexion/extension, and internal/external hip rotation (IR/ER) ROM during the football season (pre-season, mid-season, end-season). Compared to pre-season, hamstring muscle strength increased in the dominant $(+11.1 \%, p=0.002)$ and non-dominant $(+10.5 \%, p=0.014)$ limbs in the mid-season. Compared to mid-season, hamstring strength decreased in the dominant $(-9.3 \%$, $p=0.034)$ limb at end-season. Compared to the pre-season, hip extension ROM decreased in midseason in the dominant $(-31.7 \%, p=0.007)$ and non-dominant $(-44.1 \%, p=0.004)$ limbs, and further decreased at end-season $(-49.0 \%, p=0.006$ and $-68.0 \%, p<0.001)$ for the dominant and non-dominant limbs. Interlimb asymmetry for hip IR ROM increased by $57.8 \%(p<0.002)$ from pre-season to mid-season. In summary, while hamstring muscle strength increased during the first half of the football season in football players, a progressive reduction in hip extension ROM was observed throughout the season. The reduced hip extension ROM suggests a reduced mobility of the hip flexors, e.g., iliopsoas, produced by the continuous practice of football. Consequently, hip-specific stretching and conditioning exercises programs should be implemented during the football season.
\end{abstract}

Keywords: soccer; muscle injury; fatigue; team sport; flexibility; elite athlete

\section{Introduction}

Hamstring muscle injury is a very common type of injury in professional football (also known as soccer in some countries) [1]. A previous study showed that a professional football team of 25 players could expect between 5-7 hamstring muscle injuries per season [2]. Further, the incidence of hamstring muscle injuries in professional football increases over time, at a rate of $2.3 \%$ per year [2]. Hamstring muscle strain injuries cause an important loss of time from football training and competition, and result in significant impact on team performance, with long-term financial implications as a result of player unavailability [3]. 
Thus, preventing hamstring muscle injury in football might have a critical importance for overall football performance, and for the well-being of professional football players.

To implement preventive strategies during football practice, the identification of risk factors associated with hamstring muscle injury is paramount [4]. It is well recognized that the probability of suffering a muscle injury is determined by the interaction between a number of non-modifiable and modifiable extrinsic and intrinsic risk factors [5]. Amongst the modifiable risk factors, hamstring muscle strength asymmetry [6], hamstring muscle strength deficit [7], and low hamstring-to-quadriceps strength ratios [6] have been identified as factors that increase the likelihood of suffering a hamstring muscle injury in team sports. Furthermore, team players with restricted range of motion (ROM) at the hip [8] and at the ankle [9] appear to be at elevated risk of sustaining hamstring muscle injury. Altogether, this information suggests that screening of both muscle strength and flexibility in the lower limb, to detect players with deficits and asymmetries in these two risk factors, may be important to prevent hamstring muscle injury during football practice and match-play.

Despite the above mentioned risk factors, other studies have failed to associate hamstring muscle injury with strength and flexibility deficits $[10,11]$. The differences in the outcomes of these investigations might be attributable to variations in the methodology used for muscle strength and/or injury assessment [5], and the time of the season when hamstring muscle strength and hip and ankle ROM have been examined [12]. Interestingly, Noya-Salces and coworkers [13] reported that injury incidence progressively increased during the football season due to chronic fatigue developed by the continuous training and competition. The gradual reduction in physical performance in football players could be attributed to the physiological stress imposed during the competitive season [14], together with a reduction in the time allocated for muscle strength training [15]. However, there is a lack of studies describing the effect of an entire season on modifiable risk factors associated with hamstring muscle injury. Therefore, the aim of the present study was to examine the effect of regular football training and match-play during a complete season on hamstring muscle strength and hip and ankle ROM in well-trained football players. We hypothesized that hamstring muscle strength and hip ROM would be lower in the pre-season due to detraining effects caused by the transition period. Further, it was hypothesized that maximal muscle strength and hip ROM would increase from pre-season to mid-season due to the intensified and condensed period of match-play, and that these parameters would remain relatively constant during the latter half of the season.

\section{Materials and Methods}

\subsection{Participants}

A total of 26 semi-professional football players volunteered to participate in the investigation. Participants had an age (mean \pm SD) of $20.1 \pm 1.9$ years, a height of $176.9 \pm 0.1 \mathrm{~cm}$, a body mass of $72.4 \pm 6.1 \mathrm{~kg}$, and a body fat percentage of $10.7 \pm 0.8 \%$. Overall, $18(69.2 \%)$ players had right lower-limb dominance while $8(30.8 \%)$ had left lower-limb dominance. The following criterions of exclusion were adopted: a) history of pain within the previous month prior to testing; b) not regular training during the month prior to testing; c) musculoskeletal lower limb injury in three months prior to testing. Goalkeepers were excluded from the analysis. Another three field players were also excluded from the study sample because they sustained serious injuries ( $>28$ days of recovery needed for full participation in training and competition) during the season. Initially, we carried out a sample size calculation by using previous data on isometric hamstring muscle strength, and the difference in this value between injured and uninjured football players $[6,16]$. Before the start of this investigation, all players were fully informed about the testing and a written informed consent was obtained. This investigation was performed in accordance with the latest version of the Declaration of Helsinki 2013 and was approved by the Ethics Review Committee of the University. 


\subsection{Training Information}

Players had been training an average of $13.0 \pm 2.2 \mathrm{~h}$ /week across the full season, including all football training activities conducted in their clubs. The team's physical coach collected in each training session and match the rate of perceived exertion (1-10-point scale) and the exercise time on an individual basis to calculate the session RPE (sRPE) [17]. The sRPE method takes into consideration both the intensity and the duration of a training session [18]. The week-long cumulative internal workload was calculated for each player by summarizing all sRPE scores recorded for the week (including the competition, measured in arbitrary units; a.u.). As part of their training activities, participants usually performed five days of field training which included physical conditioning exercises, small-sided games, skill-based routines, and tactical exercises. In addition, players performed a strength-based training program with free-weights with two macrocycles: the first one, mainly aimed to produce strength gains, was carried out from August to December, and included two strength training sessions per week. The training sessions in this first macrocycle consisted of four exercises (half-squat, bench press, seated leg curl, and seated row machine) with a load individually set at $\sim 80 \%$ of participant's one maximum repetition (1RM), and participants performed two series of $4-5$ repetitions per exercise. The second macrocycle, which mainly aimed to maintain achieved strength levels, was performed from January to June, and included single weekly strength training sessions. The sessions consisted of four exercises (half-squat, lat pulldown, dead lift, and push press) at $~ 60 \%$ 1RM performed in two series of 6-8 repetitions per exercise. In both of these macrocycles, the strength-based session was carried using a standardized warm-up protocol that included $10 \mathrm{~min}$ of aerobic exercise (treadmill running or stationary cycling followed by two sets of six repetitions of bodyweight exercises, such as forward lunges, lateral lunges, submaximal jumps, push-ups, and trunk rotations, with a $15 \mathrm{~s}$ rest period between sets). All repetitions were performed at maximal intentional velocity for the concentric phase of the movement (with $\sim 1 \mathrm{~s}$ for the eccentric phase and for the pause between repetitions), irrespective of the macrocycle or the exercise, with at least 3 min of recovery between series and between exercises. Additionally, all the strength-based sessions were carried out before the players performed a second training session within the same day consisting of field football-specific exercises.

\subsection{Experimental Approach}

In this prospective and observational investigation, testing was performed by two experienced members of the teams' medical staff. During the whole season (10 months), the football players were tested at three different occasions: first week of the pre-season (July), which started after five weeks of a transition period with cessation of training [19]; at mid-season (first week of January), when players had competed 17 official matches; and by the end of the football season (last week of May), after completing the competitive season (38 official competitive games). At each time point (pre, mid, and end-season), players were evaluated for basic anthropometry including an estimation of fat mass by using the measurement of six skinfolds (triceps, subscapular, umbilicus, suprailium, thigh, and lower leg) and the formulae provided by Carter [20]. Afterwards, maximal isometric hamstring muscle strength, passive hip flexion ROM, hip extension ROM, hip IR ROM, and hip ER ROM were measured following this order. After this, ankle dorsiflexion ROM was assessed. All measurements were performed both in the dominant and non-dominant limbs, and they were performed in the morning (between 9:00 a.m. and 13:00 p.m.). One week prior to data collection, all study participants performed two separate familiarization trials to minimize the potential influence of learning effects on the outcomes of the investigation. In the case of the mid-season and end-season measurements, the measurement day was conducted at least $72 \mathrm{~h}$ after the last official match in order reduce the influence of fatigue in the variables under investigation [21]. 


\subsection{Measurements}

\subsubsection{Hamstring Muscle Strength}

Maximal isometric hamstring muscle strength was measured by means of a handheld dynamometer (Lafayette Instrument Company, Lafayette, IN, USA), which was calibrated prior to each measurement. Prior to testing, all football players performed a standardized warm-up that consisted of 10 min of treadmill running, followed by two sets of six repetitions of forward lunges and lateral lunges, and two isometric repetitions of hamstring muscle contractions at $\sim 50 \%$ and $\sim 75 \%$ of self-perceived peak strength, separated by $20 \mathrm{~s}$ of recovery, and in the same position as the one used for testing. Carefully adopting previous procedures [22], three maximal voluntary contraction (MVC) attempts were performed for each limb, with a 30-s rest period between repetitions. During the MVC procedure the hip joint angle was $0^{\circ}$, while the knee joint angle was $15^{\circ}$, as previously recommended [23], and the dynamometer load cell was fixed $5 \mathrm{~cm}$ proximally to the lateral malleolus using a rigid strap. Each contraction was maintained at a maximal effort for $5 \mathrm{~s}$, and the highest MVC value $(N)$ in each trial was identified. Strong verbal encouragement was provided during all tests. The MVC attempt with the highest force value was selected for subsequent analysis. The intraclass correlation coefficient (ICC) for this test ranged from 0.86 to 0.88 [22].

\subsubsection{Hip Range of Motion (ROM)}

Maximal range of motion (ROM) during passive hip flexion, hip extension, hip IR, and hip ER was measured using an inclinometer (ISOMED, Kirkland, WA, USA) with a telescopic arm, as described by Moreno-Pérez et al. [24]. Specifically, the inclinometer was placed approximately over the external malleolus for hip flexion ROM measurement, on the greater trochanter of the femur for hip extension ROM measurement, and the midpoint of the distal end of the fibula for hip IR and ER ROM measurements. In all of these measurements, the distal arm of the inclinometer was aligned parallel to an imaginary bisector line of the limb under testing. An assistant was responsible for proper stabilization of the pelvis during the measurements. The end point of each stretch was considered when the player felt a strong but tolerable stretch, before the onset of pain. Each measurement was performed twice for both legs with a $45 \mathrm{~s}$ rest period between measurements and limbs. The highest ROM value for each measurement was used in the subsequent analysis. The ICC for these tests ranged from 0.86 to $0.97[25,26]$.

\subsubsection{Ankle Dorsiflexion}

Unilateral ankle dorsiflexion ROM was assessed as described by Calatayud et al. [27] using the Leg-Motion system test (LegMotion, Check your Motion, Albacete, Spain). For this measurement, football players were in a standing position with the tested foot on the measurement scale and with their hands on their hips. The contralateral foot was positioned out of the platform with toes at the edge of it. Each participant performed the test with the assigned foot on the middle of the longitudinal line of the measurement scale, and just behind the transversal line that indicates the "zero" position. On command, participants were instructed to flex forward the knee to contact a metal stick of $70 \mathrm{~cm}$ of height, which was moved on the measurement scale until the participants could no longer maintain the heel on the ground. The distance obtained from the "zero" position to the metal stick was measured and recorded. A total of three repetitions were performed in each limb with $10 \mathrm{~s}$ of passive recovery between trials. The best score (largest ROM) among these measurements was selected for subsequent analysis. The ICC of the LegMotion System test was 0.96 to 0.98 [27].

\subsection{Statistical Analysis}

All statistical analysis was performed using the SPSS package (version 25, SPSS Inc., Chicago, IL, USA). Descriptive statistics including means and standard deviations were calculated for players' descriptive characteristics and for the isometric hamstring muscle strength, passive hip flexion, extension, IR, ER, and ankle dorsiflexion ROM. Furthermore, 
in each player, the ROM (hip flexion, extension, IR, ER, and ankle dorsiflexion ROM) scores were categorized as either normal or restricted, according to reference values previously reported as clinically meaningful: for passive hip flexion $\mathrm{ROM}\left(<80^{\circ}\right)$ [28], for hip extension $\left(<0^{\circ}\right)$ [29], for hip IR $\left(<25^{\circ}\right)$ [30], for hip ER $\left(<25^{\circ}\right)$ [31], and for ankle dorsiflexion (difference $>2 \mathrm{~cm}$ between ankles) [32]. Chi-square tests $\left(\chi^{2}\right)$ were used to compare the frequency of participants distributed in each category over time. Between-limb asymmetry was calculated as the percentage difference between limbs [33]. Normality of data distribution was verified using the Kolmogorov-Smirnov test. One-way repeated measures ANOVA was used to identify differences among the three moments of measurement. When a statistical significance was identified in the ANOVA, the Bonferroni post hoc test were applied to detect pairwise differences. Statistical significance was set at $p<0.05$. In addition, to determine the magnitude of differences, Cohen's effect size $(d)$ and $95 \%$ confidence intervals (CI) were calculated and interpreted as: <0.2 trivial; 0.2-0.6 small; 0.6-1.2 moderate; or $>1.2$ large [34].

\section{Results}

Football players competed, on average, of $17 \pm 10$ official matches (5-38 matches), with a total match playing time of $1465 \pm 964 \mathrm{~min}$ (range $=68-543 \mathrm{~min}$ ). Figure 1 depicts the evolution of the week-long cumulative internal workload across the season. Overall, there was a tendency for a progressive reduction on the values of sRPE.

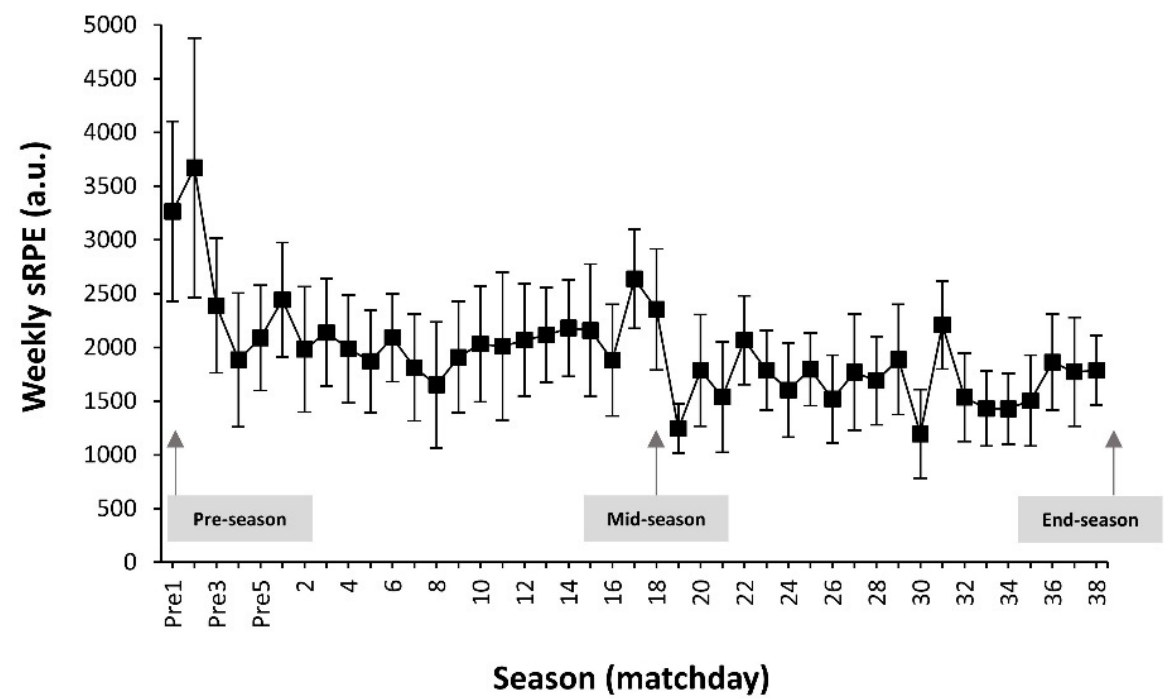

Figure 1. Week-long accumulated values of the session rate of perceived exertion (sRPE) across the season. Pre = indicates weeks without official competitions during the pre-season. The arrows indicate the moment of strength and range of motion measurement.

Hamstring muscle strength values in the pre-season, mid-season, and end-season are presented in Table 1. Comparing pre-season to mid-season, hamstring muscle strength significantly increased in both the dominant limb $(+11.1 \%, d=0.617[0.159,1.037], p=0.002)$ and in the non-dominant limb $(+10.5 \%, d=0.545$ [0.098, 0.960], $p=0.014)$. In contrast, a decrease in hamstring muscle strength was observed from mid-season to end-season in the dominant $\operatorname{limb}(-9.3 \%, d=-0.442[-0.008,-0.850], p=0.034)$. No statistically significant changes were observed in dominant and non-dominant isometric hamstring muscle strength values from start pre-season to end-season (Table 1). 
Table 1. Isometric hamstring muscle strength assessed at pre-season, mid-season, and end-season.

\begin{tabular}{|c|c|c|c|c|c|c|}
\hline $\begin{array}{l}\text { Hamstring } \\
\text { Muscle } \\
\text { Strength }\end{array}$ & Pre-Season & Mid-Season & End-Season & $\begin{array}{c}\text { Pre- vs. Mid-Season } \\
p \text { Value } \\
\text { Mean Difference } d\end{array}$ & $\begin{array}{c}\text { Pre- vs. End-Season } \\
p \text { Value } \\
\text { Mean Difference } d\end{array}$ & $\begin{array}{c}\text { Mid- vs. End-Season } p \\
\text { Value } \\
\text { Mean Difference } d\end{array}$ \\
\hline $\begin{array}{c}\text { Hamstring } \\
\text { muscle strength } \\
\text { in the dominant } \\
\text { limb }(N)\end{array}$ & $361.5 \pm 14.3$ & $406.6 \pm 16.7$ & $368.7 \pm 15.4$ & $\begin{array}{c}0.002 \\
45.09[15.84,74.35] \\
0.62[1.04,0.16] \\
\text { moderate }\end{array}$ & $\begin{array}{c}1.000 \\
7.19[-29.18,43.56] \\
0.10[-0.31,0.500] \\
\text { trivial }\end{array}$ & $\begin{array}{c}0.034 \\
-37.91[-73.44,-2.37] \\
-0.44[-0.85,-0.01] \\
\text { small }\end{array}$ \\
\hline $\begin{array}{l}\text { Hamstring } \\
\text { muscle strength } \\
\text { in the } \\
\text { non-dominant } \\
\text { limb }(N)\end{array}$ & $342.2 \pm 14.4$ & $382.3 \pm 16.1$ & $355.7 \pm 15.3$ & $\begin{array}{c}0.014 \\
40.09[7.05,73.14] \\
0.55[0.10,0.96] \\
\text { small }\end{array}$ & $\begin{array}{c}1.000 \\
13.48[-27.89,54.84] \\
0.18[-0.23,0.58] \\
\text { trivial }\end{array}$ & $\begin{array}{c}0.108 \\
-26.61[-57.45,4.22] \\
-0.33[-0.78,0.10] \\
\text { small }\end{array}$ \\
\hline
\end{tabular}

Abbreviations: $d=$ Cohen's effect size: Values between brackets are $95 \%$ confidence limits for mean difference and $d$.

Table 2 shows values of the passive hip flexion, extension, IR, and ER, together with ankle dorsiflexion ROM throughout the season. A decrease in dominant and non-dominant hip extension ROM was found from pre-season to mid-season (dominant limb $=-31.7 \%$, $d=-0.368$ [-0.057, -0.722$], p=0.007$; non-dominant $\operatorname{limb}=-44.1 \%, d=0.519[-0.075,-0.931]$, $p=0.004)$. A further decrease in the dominant and non-dominant hip extension ROM was found in the end-season measurement (Table 2). Furthermore, hip ER ROM showed a significant decrease from mid-season to end-season $(-3.0 \%, d=-0.269[-0.146,-0.670]$, $p=0.022$ ). In contrast, higher values were observed from pre-season to mid-season in hip IR ROM in the non-dominant limb $(+8.7 \%, d=0.645[0.183,1.068], p=0.028)$. No changes were observed in the remaining ROM measures, including passive ankle ROM at any time point of the season.

Table 2. Hip extension, external rotation, internal rotation, flexion, and ankle dorsiflexion ROM assessed at pre-season, mid-season, and end-season.

\begin{tabular}{|c|c|c|c|c|c|c|}
\hline Range of Motion & Pre-Season & Mid-Season & End-Season & $\begin{array}{c}\text { Pre- vs. Mid-Season } \\
p \text { Value } \\
\text { Mean Difference } d\end{array}$ & $\begin{array}{c}\text { Pre- vs. End-Season } \\
p \text { Value } \\
\text { Mean Difference } d\end{array}$ & $\begin{array}{c}\text { Mid- vs. End-Season } \\
p \text { Value } \\
\text { Mean Difference } d\end{array}$ \\
\hline $\begin{array}{l}\text { Hip Extension }\left(^{\circ}\right) \\
\text { (Dominant) }\end{array}$ & \multirow[t]{2}{*}{$5.3 \pm 0.9$} & \multirow[t]{2}{*}{$3.6 \pm 0.9$} & \multirow[t]{2}{*}{$2.7 \pm 1.0$} & $\begin{array}{c}0.007 \\
-1.692[-2.964,-0.421] \\
-0.368[-0.722,-0.057] \\
\text { small }\end{array}$ & $\begin{array}{c}0.006 \\
-2.615[-4.543,-0.668] \\
-0.569[-0.986,-0.118] \\
\text { small }\end{array}$ & $\begin{array}{c}0.611 \\
-0.923[-2.737,0.891] \\
-0.184[-0.583,0.225] \\
\text { trivial }\end{array}$ \\
\hline $\begin{array}{l}\text { Qualitative } \\
\text { outcome }\end{array}$ & & & & Normal $(0)^{\$}$ & Normal (6) & Normal (6) \\
\hline $\begin{array}{l}\text { Hip Extension }\left(^{\circ}\right) \\
\text { (Non-dominant) }\end{array}$ & \multirow[t]{2}{*}{$5.5 \pm 0.9$} & \multirow[t]{2}{*}{$3.11 \pm 0.8$} & \multirow[t]{2}{*}{$1.7 \pm 0.7$} & $\begin{array}{c}0.004 \\
-2.462[-4.212,-0.711] \\
-0.519[-0.931,-0.075] \\
\text { small }\end{array}$ & $\begin{array}{c}<0.001 \\
-3.808[-5.715,-1.901] \\
-0.778[-1.242,-0.314] \\
\text { moderate }\end{array}$ & $\begin{array}{c}0.127 \\
-1.346[-2.959,0.267] \\
-0.328[-0.730,0.093] \\
\text { small }\end{array}$ \\
\hline $\begin{array}{l}\text { Qualitative } \\
\text { outcome * }\end{array}$ & & & & Normal (4) & Normal (7) & Normal (3) \\
\hline $\begin{array}{l}\text { Hip ER }\left(^{\circ}\right) \\
\text { (Dominant) }\end{array}$ & \multirow[t]{2}{*}{$57.4 \pm 1.4$} & \multirow[t]{2}{*}{$58.71 \pm 1.2$} & \multirow[t]{2}{*}{$56.9 \pm 1.3$} & $\begin{array}{c}0.850 \\
1.288[-1.727,4.304] \\
0.173[-0.235,0.572] \\
\text { trivial }\end{array}$ & $\begin{array}{c}1.000 \\
-0.481[-3.798,2.836] \\
-0.064[-0.464,0.338] \\
\text { trivial }\end{array}$ & $\begin{array}{c}0.022 \\
-1.769[-3.324,-0.215] \\
-0.269[-0.670,-0.146] \\
\text { small }\end{array}$ \\
\hline $\begin{array}{l}\text { Qualitative } \\
\text { outcome * }\end{array}$ & & & & Normal (0) & Normal (0) & Normal (0) \\
\hline $\begin{array}{c}\text { Hip ER }\left(^{\circ}\right) \\
\text { (Non-dominant) }\end{array}$ & \multirow[t]{2}{*}{$55.9 \pm 1.4$} & \multirow[t]{2}{*}{$57.23 \pm 1.2$} & \multirow[t]{2}{*}{$58.0 \pm 1.1$} & $\begin{array}{c}0.860 \\
1.269[-1.723,4.261] \\
0.177[-0.231,0.576] \\
\text { trivial }\end{array}$ & $\begin{array}{c}0.594 \\
2.096[-1.972,6.165] \\
0.293[-0.125,0.694] \\
\text { small }\end{array}$ & $\begin{array}{c}1.000 \\
0.827[-1.723,3.377] \\
0.128[-0.278,0.526] \\
\text { trivial }\end{array}$ \\
\hline $\begin{array}{l}\text { Qualitative } \\
\text { outcome* }\end{array}$ & & & & Normal (0) & Normal (0) & Normal (0) \\
\hline $\begin{array}{l}\text { Hip IR }\left({ }^{\circ}\right) \\
\text { (Dominant) }\end{array}$ & \multirow[t]{2}{*}{$46.4 \pm 1.3$} & \multirow[t]{2}{*}{$47.9 \pm 1.1$} & \multirow[t]{2}{*}{$48.13 \pm 1.2$} & $\begin{array}{c}0.851 \\
1.462[-1.960,4.883] \\
0.212[-0.199,0.611] \\
\text { small }\end{array}$ & $\begin{array}{c}1.000 \\
1.692[-2.942,6.326] \\
0.246[-0.168,0.645] \\
\text { small }\end{array}$ & $\begin{array}{c}1.000 \\
0.231[-2.367,2.828] \\
0.039[-0.362,0.439] \\
\text { trivial }\end{array}$ \\
\hline $\begin{array}{l}\text { Qualitative } \\
\text { outcome * }\end{array}$ & & & & Normal (0) & Normal (0) & Normal (0) \\
\hline
\end{tabular}


Table 2. Cont.

\begin{tabular}{|c|c|c|c|c|c|c|}
\hline Range of Motion & Pre-Season & Mid-Season & End-Season & $\begin{array}{c}\text { Pre- vs. Mid-Season } \\
p \text { Value } \\
\text { Mean Difference } d\end{array}$ & $\begin{array}{c}\text { Pre- vs. End-Season } \\
p \text { Value } \\
\text { Mean Difference } d\end{array}$ & $\begin{array}{c}\text { Mid- vs. End-Season } \\
p \text { Value } \\
\text { Mean Difference } d\end{array}$ \\
\hline $\begin{array}{c}\text { Hip IR }\left(^{\circ}\right) \\
\text { (Non-dominant) }\end{array}$ & \multirow[t]{2}{*}{$47.4 \pm 1.3$} & \multirow[t]{2}{*}{$51.94 \pm 1.4$} & \multirow[t]{2}{*}{$51.09 \pm 1.4$} & $\begin{array}{c}0.028 \\
4.538[0.410,8.667] \\
0.645[0.183,1.068] \\
\text { moderate }\end{array}$ & $\begin{array}{c}0.108 \\
3.692[-0.579,7.964] \\
0.525[-0.080,0.938] \\
\text { moderate }\end{array}$ & $\begin{array}{c}1.000 \\
-0.846[-3.066,-1.374] \\
-0.111[-0.509,0.294] \\
\text { trivial }\end{array}$ \\
\hline $\begin{array}{l}\text { Qualitative } \\
\text { outcome* }\end{array}$ & & & & Normal (0) & Normal (0) & Normal (0) \\
\hline $\begin{array}{c}\text { Hip Flexion }\left(^{\circ}\right) \\
\text { (Dominant) }\end{array}$ & \multirow[t]{2}{*}{$73.5 \pm 1.2$} & \multirow[t]{2}{*}{$72.0 \pm 1.1$} & \multirow[t]{2}{*}{$71.4 \pm 1.0$} & $\begin{array}{c}0.296 \\
-1.577[-3.935,0.781] \\
-0.245[-0.644,0.169] \\
\text { small }\end{array}$ & $\begin{array}{c}0.123 \\
-2.096[4.592,0.400] \\
-0.326[-0.750,0.095] \\
\text { small }\end{array}$ & $\begin{array}{c}1.000 \\
-0.519[-2.105,1.067] \\
-0.089[-0.488,0.314] \\
\text { trivial }\end{array}$ \\
\hline $\begin{array}{l}\text { Qualitative } \\
\text { outcome* }\end{array}$ & & & & Normal (3) & Normal (5) & Normal (2) \\
\hline $\begin{array}{l}\text { Hip Flexion }\left(^{\circ}\right) \\
\text { (Non-dominant) }\end{array}$ & \multirow[t]{2}{*}{$72.9 \pm 1.2$} & \multirow[t]{2}{*}{$71.7 \pm 0.9$} & \multirow[t]{2}{*}{$72.2 \pm 0.9$} & $\begin{array}{c}0.748 \\
-1.231[-3.909,1.447] \\
-0.186[-0.585,0.223] \\
\text { trivial }\end{array}$ & $\begin{array}{c}1.000 \\
-0.731[-4.136,2.674] \\
-0.110[-0.509,0.294] \\
\text { trivial }\end{array}$ & $\begin{array}{c}1.000 \\
0.500[-1.418,2.418] \\
0.102[-0.300,0.501] \\
\text { trivial }\end{array}$ \\
\hline $\begin{array}{l}\text { Qualitative } \\
\text { outcome* }\end{array}$ & & & & Normal (6) & Normal (6) & Normal (0) $\$$ \\
\hline $\begin{array}{c}\text { Ankle dorsiflexion } \\
(\mathrm{cm}) \\
\text { (Dominant) }\end{array}$ & \multirow[t]{2}{*}{$11.0 \pm 0.3$} & \multirow[t]{2}{*}{$10.9 \pm 0.3$} & \multirow[t]{2}{*}{$10.4 \pm 0.3$} & $\begin{array}{c}1.000 \\
-0.173[-0.898,0.552] \\
-0.090[-0.489,0.314] \\
\text { trivial }\end{array}$ & $\begin{array}{c}0.406 \\
-0.663[-1.767,0.440] \\
-0.346[-0.748,0.077] \\
\text { small }\end{array}$ & $\begin{array}{c}0.541 \\
-0.490[-1.403,0.423] \\
-0.309[-0.711,0.110] \\
\text { small }\end{array}$ \\
\hline $\begin{array}{l}\text { Qualitative } \\
\text { outcome* }\end{array}$ & & & & Normal $(0)^{\$}$ & Normal (2) & Normal (7) $\$$ \\
\hline $\begin{array}{l}\text { Ankle dorsiflexion } \\
(\mathrm{cm}) \\
\text { (Non-dominant) }\end{array}$ & \multirow[t]{2}{*}{$10.8 \pm 0.4$} & \multirow[t]{2}{*}{$11.4 \pm 0.3$} & \multirow[t]{2}{*}{$11.0 \pm 0.4$} & $\begin{array}{c}0.517 \\
0.625[-0.517,1.767] \\
0.286[-0.131,0.686] \\
\text { small }\end{array}$ & $\begin{array}{c}1.000 \\
0.231[-1.140,1.602] \\
0.105[-0.299,0.504] \\
\text { trivial }\end{array}$ & $\begin{array}{c}0.733 \\
-0.394[-1.242,0.459] \\
-0.212[-0.611,0.199] \\
\text { small }\end{array}$ \\
\hline $\begin{array}{l}\text { Qualitative } \\
\text { outcome* }\end{array}$ & & & & Normal (1) & Normal (1) & Normal (3) \\
\hline
\end{tabular}

Abbreviations: $d=$ Cohen's effect size: Values between brackets are $95 \%$ confidence limits for mean difference and $d .{ }^{*}$ Qualitative score of the mean range of motion, in parentheses the number of players with a restricted range of motion score according to previously published cut-off scores (see Section 2.5); ${ }^{\$}=$ Depicts that the frequency of football players categorized as "normal" was different from the expected value at $p<0.05$.

Table 3 depicts bilateral differences in the investigated variables. The only change during the season was an increase in the side-to-side difference for hip IR ROM from pre-season to mid-season $(+57.8 \%, d=0.795[0.329,1.262], p=0.002)$.

Table 3. Bilateral differences (dominant vs. non-dominant) for isometric hamstring muscle strength passive hip flexion, extension, external rotation, internal rotation, and ankle dorsiflexion ROM assessed at pre-season, mid-season, and end-season.

\begin{tabular}{|c|c|c|c|c|c|c|}
\hline $\begin{array}{l}\text { Bilateral Difference } \\
\text { (Dominant vs. } \\
\text { Non-Dominant) }\end{array}$ & Pre-Season & Mid-Season & End-Season & $\begin{array}{c}\text { Pre- vs. Mid-Season } \\
p \text { Value } \\
\text { Mean Difference } d\end{array}$ & $\begin{array}{c}\text { Pre- vs. End-Season } \\
p \text { Value } \\
\text { Mean Difference } d\end{array}$ & $\begin{array}{c}\text { Mid- vs. End-Season } \\
p \text { Value } \\
\text { Mean Difference } d\end{array}$ \\
\hline $\begin{array}{l}\text { Isometric Hamstring } \\
\text { strength }(\%)\end{array}$ & $13.0 \pm 8.1$ & $12.2 \pm 9.8$ & $10.9 \pm 8.8$ & $\begin{array}{c}1.000 \\
-0.818[-7.006,5.371] \\
-0.097[-0.499,0.304] \\
\text { trivial }\end{array}$ & $\begin{array}{c}0.846 \\
-2.120[-7.067,2.826] \\
-0.253[-0.661,0.154] \\
\text { small }\end{array}$ & $\begin{array}{c}1.000 \\
-1.303[-8.183,5.578] \\
-0.127[-0.530,0.274] \\
\text { trivial }\end{array}$ \\
\hline Hip Extension ROM (\%) & $37.1 \pm 34.0$ & $30.6 \pm 40.4$ & $53.8 \pm 39.4$ & $\begin{array}{c}1.000 \\
-6.553[-32.766,19.660] \\
-0.185[-0.590,0.218] \\
\text { trivial }\end{array}$ & $\begin{array}{c}0.424 \\
16.707[-11.516,44.931] \\
0.473[-0.048,0.899] \\
\text { small }\end{array}$ & $\begin{array}{c}1.000 \\
23.260[-5.741,52.262] \\
0.557[-0.123,0.991] \\
\text { small }\end{array}$ \\
\hline Hip ER ROM (\%) & $6.5 \pm 6.3$ & $6.7 \pm 7.1$ & $8.89 \pm 6.4$ & $\begin{array}{c}1.000 \\
0.254[-2.605,3.112] \\
0.038[-0362,0.439] \\
\text { small }\end{array}$ & $\begin{array}{c}0.172 \\
2.387[-0.688,5.462] \\
0.364[-0.051,0.779] \\
\text { small }\end{array}$ & $\begin{array}{c}0.238 \\
2.133[-0.859,5.126] \\
0.289[-0.120,0.699] \\
\text { small }\end{array}$ \\
\hline Hip IR ROM (\%) & $5.9 \pm 5.2$ & $10.3 \pm 7.3$ & $9.5 \pm 7.0$ & $\begin{array}{c}0.002 \\
4.341[1.413,7.269] \\
0.795[0.329,1.262] \\
\text { moderate }\end{array}$ & $\begin{array}{c}0.065 \\
3.540[-0.169,7.249] \\
0.649[-0.023,1.094] \\
\text { moderate }\end{array}$ & $\begin{array}{c}1.000 \\
-0.801[-5.171,3.569] \\
-0.105[-0.507,0.296] \\
\text { trivial }\end{array}$ \\
\hline
\end{tabular}


Table 3. Cont.

\begin{tabular}{|c|c|c|c|c|c|c|}
\hline $\begin{array}{l}\text { Bilateral Difference } \\
\text { (Dominant vs. } \\
\text { Non-Dominant) }\end{array}$ & Pre-Season & Mid-Season & End-Season & $\begin{array}{c}\text { Pre- vs. Mid-Season } \\
p \text { Value } \\
\text { Mean Difference } d\end{array}$ & $\begin{array}{c}\text { Pre- vs. End-Season } \\
p \text { Value } \\
\text { Mean Difference } d\end{array}$ & $\begin{array}{c}\text { Mid- vs. End-Season } \\
p \text { Value } \\
\text { Mean Difference } d\end{array}$ \\
\hline Hip Flexion ROM (\%) & $4.0 \pm 3.1$ & $3.6 \pm 3.9$ & $4.0 \pm 3.4$ & $\begin{array}{c}1.000 \\
-0.346[-1.850,1.158] \\
-0.105[-0.507,0.297] \\
\text { trivial }\end{array}$ & $\begin{array}{c}1.000 \\
0.093[-2.146,2.331] \\
0.028[-0.372,0.429] \\
\text { trivial }\end{array}$ & $\begin{array}{c}1.000 \\
0.439[-1.857,2.734] \\
0.108[-0.293,0.510] \\
\text { trivial }\end{array}$ \\
\hline $\begin{array}{l}\text { Ankle dorsiflexion } \\
\text { ROM }(\%)\end{array}$ & $7.46 \pm 7.2$ & $10.0 \pm 8.9$ & $10.5 \pm 6.8$ & $\begin{array}{c}0.794 \\
2.586[-3.241,8.414] \\
0.344[-0.069,0.758] \\
\text { small }\end{array}$ & $\begin{array}{c}0.403 \\
3.089[-2.035,8.214] \\
0.411[-0.007,0.831] \\
\text { small }\end{array}$ & $\begin{array}{c}1.000 \\
0.503[-5.197,6.203] \\
0.054[-0.346,0.455] \\
\text { trivial }\end{array}$ \\
\hline
\end{tabular}

Abbreviations: $d=$ Cohen's effect size: Values between brackets are 95\% confidence limits for mean difference and $d$.

\section{Discussion}

The aim of this study was to examine the longitudinal effect of football training and match-play during a complete football season on hamstring muscle strength and hip and ankle ROM in semi-professional football players. The rationale for this investigation was based on previous reports suggesting that weakness in hamstring muscles is an important risk factor associated with the development of hamstring muscle strain injury [7], with an additional contribution from reduced ROM at the hip [8] and ankle joints [9]. Confirming our hypothesis, hamstring muscle strength was lower in the pre-season than in the midseason, but an unexpected decline in hamstring muscle strength was found from mid-season to end-season measurements, especially in the dominant limb. Additionally, our hypothesis about the maintenance of hip ROM variables during the latter half of the season could not be verified, as hip extension ROM decreased across the season for both the dominant and non-dominant limbs.

However, to the best of our knowledge, no previous investigation has evaluated the longitudinal modulation in hamstring muscle strength and hip/ankle flexibility across the competitive season of football athletes. The present data revealed that hamstring muscle strength increased at mid-season testing compared with pre-season levels in both the dominant and non-dominant limbs, while it returned to baseline levels by the end of the season. This outcome generally agrees with the finding of Wollin et al. [35], who reported that hip adductor strength and adductor/abductor strength ratio were lowest at pre-season, and they gradually increased during the weeks of intervention as players adapted to the demands of the training program. In the current investigation, players arrived from a fiveweek transition before the pre-season testing, while the transition period was characterized by complete cessation of all training activities, as previously suggested $[19,36]$. Interestingly, the workload of the weeks that conformed the pre-season period induced high ratings of perceived fatigue due to the detrained status of players, and due to the lack of lower intensity/lower volume sessions to prepare official matches or to recover from the match. This combination of factors ultimately indicated that the highest levels in weekly cumulative workload were reached in the preseason period (Figure 1). Overall, these data suggest that football players might be more prone to hamstring muscle injury during football practice in the pre-season phase due to initial detraining effects caused by the transition period, potentially resulting in reduced hamstring muscle strength, together with a higher training workload. Interestingly, the strength deficit may be overcome during the mid-season as a positive result of the football training and physical conditioning performed during this phase of the season.

On the other hand, a significant reduction in hamstring muscle strength of the dominant limb was observed at end-season compared with mid-season in the present group of football players. Providing a possible explanation for this reduction, the study participants may have experienced a physical deconditioning effect due to a reduced of overall training workload and particularly in the number of strength training sessions performed in the last part of the season (i.e., the last four weeks of the competitive season). Figure 1 indicates that a slight but progressive reduction in weekly training workload occurred during the season, 
assessed by a composite variable that included internal (RPE) and external (exercise time) loads. This reduction of the training workload was induced by the necessity of increasing the number of recovery sessions per week as the result of the chronic workload along with the accumulated number of official matches. Of note, as indicated in the methodology, the frequency of strength training sessions was also reduced from twice per week to once per week from February until the end of the season, together with a reduction in the load set per exercise. This information suggests that the football players examined in the present investigation might have experienced a physical deconditioning towards the end of the season as the result of reduced training load during training aimed to offset cumulative fatigue $[14,15]$. These data suggest that, in addition to the preseason, the end-season phase may increase the likelihood of suffering a hamstring muscle injury during football practice or match-play.

The present study observed a decrease in hip extension ROM from pre-season to mid-season that was further decreased in the end-season (Table 1). In addition, the current results showed a significant decrease of hip ER ROM from mid-season to end-season in the dominant limb. Interestingly, 6 out of 26 players $(23 \%)$ developed a restriction in hip extension ROM in the mid-season, while this restriction was maintained at the endseason in these players. In addition, 7 out of 26 players (27\%) presented restricted ankle dorsiflexion in the dominant limb at the end of season (Table 1). To our best knowledge, no previous studies have evaluated the longitudinal effects of football training and match-play within an entire season on hip ROM, although a single study exists for ankle dorsiflexion ROM [37]. A possible explanation for the present reductions in passive hip extension ROM in our group of football players across the competitive season might be due to adaptations in the muscle-tendon complex induced by the large number of high-force movements tasks performed during training and matches. Football is an intermittent sport where players often perform sport specific motor tasks at maximum intensity, such as rapid accelerations, decelerations, changes of direction, jumping, and landing tasks that all involve coupled eccentric-concentric muscle actions (so-called stretch-shortening cycles: SSC) [38]. It is well known that longitudinal exposure to high-intensity eccentric muscle actions increases the stiffness of muscles and tendons [39] and decreases joint ROM [40]. Thus, the massive involvement of SSC muscle actions during the football season could be an explanation for the reduction in hip extension ROM.

The observation of no alterations in ankle dorsiflexion ROM throughout the football season in the present study differ from report by Moreno-Pérez et al. [37], who found a progressive reduction in ankle dorsiflexion ROM when assessed during a competitive football season. This lack of agreement between studies may be due to differences in external load demands during the season. For instance, Moreno-Pérez et al. [37] included 40 professional players who performed $30.8 \pm 9.9$ matches per season, covering $2222 \pm 844 \mathrm{~min} /$ season, whereas the present players demonstrated a much lower match load (17 matches, $1440 \mathrm{~min}$ for players participating full time in all matches). Consequently, the magnitude of cumulative match loading might be a governing factor for the effect of competitive football on ankle dorsiflexion ROM.

Based on previous study reports [41,42], the existence of between-limb strength or/and ROM asymmetries are associated with a higher likelihood of developing lower-limb injuries in football players. The present study revealed a greater difference in hip IR ROM between dominant and non-dominant limbs from pre-season to mid-season. This result is possibly due to the asymmetrical participation of the lower limbs during football practice [38]. Specifically, football players typically repeat technical gestures of kicking, side cutting, and controlling the ball mainly using the dominant limb while the other limb is used to support the body weight during these actions [43]. Consequently, an increased focus should be made to maintain hip IR ROM in the dominant limb throughout the football season, especially in players who perform a large number of kicking actions during the season. 


\section{Study Limitations}

The current study has several limitations that should be acknowledged. Firstly, as the current study has been performed in a specific sample of football players with a defined match and training load, the present findings may not be readily extended to other populations of high-level team sport athletes. In addition, although all players underwent the same training program, there were large differences in the match load among players. Further, the present outcome variables were obtained relatively infrequent (three times) during the competitive season, and the measurement of quadriceps muscle strength was not included in this study. Future studies could benefit from assessing hamstring muscle strength and passive hip and ankle ROM using more high-frequent protocols, and by studying the fluctuations of quadriceps muscle strength and hamstring-to-quadriceps ratio throughout the season. Lastly, although the current study included the measurement of several potential risk factors for hamstring and groin injury, no prospective measurement of these type of injury were measured in the present study sample. Future studies should evaluate whether the fluctuations in hamstring strength and hip mobility presented here are associated with corresponding fluctuations in the incidence of hamstring and groin injury, particularly during the second half of the season.

\section{Conclusions}

In summary, hamstring muscle strength was observed to fluctuate substantially in semi-professional players across the football season. Overall, football training produced enhancements in hamstring muscle strength during the mid-season, while the pre-season and end-season periods both may represent periods with increased risk of hamstring muscle injury due to low levels of hamstring muscle strength. In addition, the current study found a gradual reduction in hip extension ROM during the competitive season, pointing towards a progressively increased hip flexor stiffness as a result of the accumulated volume of training and match-play. This latter observation might suggest an increased risk of groin injury towards the latter half of the season. Collectively, the present data confirm the necessity of prescribing a preventive injury program aimed at maintaining stable levels of hamstring strength and hip mobility throughout the season in order to prevent groin and hamstring injury $[44,45]$, as players demonstrate fluctuations in these variables as the result of their exposure to football training and competition.

Author Contributions: Conceptualization, V.M.-P., G.R., M.P.-M., Á.L.-S., D.R.-R., P.A. and J.D.C.; methodology, V.M.-P. and M.P.-M.; formal analysis, V.M.-P., G.R., M.P.-M., Á.L.-S., D.R.-R., P.A. and J.D.C.; writing—original draft preparation, V.M.-P., Á.L.-S. and J.D.C.; writing—review and editing, V.M.-P., G.R., M.P.-M., Á.L.-S., D.R.-R., P.A. and J.D.C. All authors have read and agreed to the published version of the manuscript.

Funding: This research received no external funding.

Institutional Review Board Statement: The study was conducted in accordance with the Declaration of Helsinki and approved by the Institutional Review Board of the Miguel Hernandez University of Elche (DPC.VMP.01.18, 16 January 2017).

Informed Consent Statement: Informed consent was obtained from all subjects involved in the study.

Data Availability Statement: The data presented in this study are available on request from the corresponding author. The data are not publicly available due to restrictions of the club where the data were obtained.

Acknowledgments: The authors would like to express their gratitude to the medical staff from collection data and football players who participated in the study.

Conflicts of Interest: The authors declare no conflict of interest. 


\section{References}

1. Ekstrand, J.; Hägglund, M.; Waldén, M. Injury incidence and injury patterns in professional football: The UEFA injury study. Br. J. Sports Med. 2011, 45, 553-558. [CrossRef] [PubMed]

2. Ekstrand, J.; Waldén, M.; Hägglund, M. Hamstring injuries have increased by $4 \%$ annually in men's professional football, since 2001: A 13-year longitudinal analysis of the UEFA Elite Club injury study. Br. J. Sports Med. 2016, 50, 731-737. [CrossRef] [PubMed]

3. Eirale, C.; Tol, J.L.; Farooq, A.; Smiley, F.; Chalabi, H. Low injury rate strongly correlates with team success in Qatari professional football. Br. J. Sports Med. 2013, 47, 807-808. [CrossRef] [PubMed]

4. Hägglund, M.; Waldén, M.; Ekstrand, J. Risk factors for lower extremity muscle injury in professional soccer: The UEFA injury study. Am. J. Sports Med. 2013, 41, 327-335. [CrossRef] [PubMed]

5. Mendiguchia, J.; Alentorn-Geli, E.; Brughelli, M. Hamstring strain injuries: Are we heading in the right direction? Br. J. Sports Med. 2012, 46, 81-85. [CrossRef]

6. $\quad$ Lee, J.W.Y.; Mok, K.M.; Chan, H.C.K.; Yung, P.S.H.; Chan, K.M. Eccentric hamstring strength deficit and poor hamstring-toquadriceps ratio are risk factors for hamstring strain injury in football: A prospective study of 146 professional players. J. Sci. Med. Sport 2018, 21, 789-793. [CrossRef]

7. Timmins, R.G.; Bourne, M.N.; Shield, A.J.; Williams, M.D.; Lorenzen, C.; Opar, D.A. Short biceps femoris fascicles and eccentric knee flexor weakness increase the risk of hamstring injury in elite football (soccer): A prospective cohort study. Br. J. Sports Med. 2016, 50, 1524-1535. [CrossRef]

8. Bradley, P.S.; Portas, M.D. The relationship between preseason range of motion and muscle strain injury in elite soccer players. J. Strength Cond. Res. 2007, 21, 1155-1159.

9. Gabbe, B.J.; Bennell, K.L.; Finch, C.F.; Wajswelner, H.; Orchard, J.W. Predictors of hamstring injury at the elite level of Australian football. Scand. J. Med. Sci. Sports 2006, 16, 7-13. [CrossRef]

10. Prior, M.; Guerin, M.; Grimmer, K. An evidence-based approach to hamstring strain injury: A systematic review of the literature. Sports Health 2009, 1, 154-164. [CrossRef]

11. Arnason, A.; Sigurdsson, S.B.; Gudmundsson, A.; Holme, I.; Engebretsen, L.; Bahr, R. Risk Factors for Injuries in Football. Am. J. Sports Med. 2004, 32, 5-16. [CrossRef] [PubMed]

12. Wollin, M.; Thorborg, K.; Pizzari, T. The acute effect of match play on hamstring strength and lower limb flexibility in elite youth football players. Scand. J. Med. Sci. Sports 2017, 27, 282-288. [CrossRef] [PubMed]

13. Noya Salces, J.; Gomez-Carmona, P.M.; Moliner-Urdiales, D.; Gracia-Marco, L.; Sillero-Quintana, M. An examination of injuries in Spanish Professional Soccer League. J. Sports Med. Phys. Fit. 2014, 54, 765-771.

14. Silva, J.R.; Magalhães, J.F.; Ascensão, A.A.; Oliveira, E.M.; Seabra, A.F.; Rebelo, A.N. Individual match playing time during the season affects fitness-related parameters of male professional soccer players. J. Strength Cond. Res. 2011, 25, 2729-2739. [CrossRef]

15. Rønnestad, B.R.; Nymark, B.S.; Raastad, T. Effects of inseason strength maintenance training frequency in professional soccer players. J. Strength Cond. Res. 2011, 25, 2653-2660. [CrossRef] [PubMed]

16. Peek, K.; Gatherer, D.; Bennett, K.J.M.; Fransen, J.; Watsford, M. Muscle strength characteristics of the hamstrings and quadriceps in players from a high-level youth football (soccer) Academy. Res. Sports Med. 2018, 26, 276-288. [CrossRef]

17. Foster, C.; Florhaug, J.A.; Franklin, J.; Gottschall, L.; Hrovatin, L.A.; Parker, S.; Doleshal, P.; Dodge, C. A new approach to monitoring exercise training. Une Nouvelle approche pour conduire l'entrainement. J. Strength Cond. Res. 2001, 15, 109-115.

18. Haddad, M.; Stylianides, G.; Djaoui, L.; Dellal, A.; Chamari, K. Session-RPE Method for Training Load Monitoring: Validity, Ecological Usefulness, and Influencing Factors. Front. Neurosci. 2017, 11, 612. [CrossRef]

19. Mujika, I.; Padilla, S. Detraining: Loss of training-induced physiological and performance adaptations. Part II: Long term insufficient training stimulus. Sports Med. 2000, 30, 145-154. [CrossRef]

20. Carter, J.E.L. Part 1: The Heath-Carter Anthropometric Somatotype-Instruction Manual; TeP and ROSSCRAFT: Surrey, BA, Canada, 2002.

21. Silva, J.R.; Rumpf, M.C.; Hertzog, M.; Castagna, C.; Farooq, A.; Girard, O.; Hader, K. Acute and Residual Soccer Match-Related Fatigue: A Systematic Review and Meta-analysis. Sports Med. 2018, 48, 539-583. [CrossRef]

22. Thorborg, K.; Petersen, J.; Magnusson, S.P.; Hölmich, P. Clinical assessment of hip strength using a hand-held dynamometer is reliable. Scand. J. Med. Sci. Sports 2010, 20, 493-501. [CrossRef] [PubMed]

23. van der Made, A.D.; Paget, L.D.A.; Altink, J.N.; Reurink, G.; Six, W.R.; Tol, J.L.; Kerkhoffs, G.M. Assessment of Isometric Knee Flexor Strength Using Hand-Held Dynamometry in High-Level Rugby Players Is Intertester Reliable. Clin. J. Sport Med. 2021, 31, e271-e276. [CrossRef] [PubMed]

24. Moreno-Pérez, V.; Ayala, F.; Fernandez-Fernandez, J.; Vera-Garcia, F.J. Descriptive profile of hip range of motion in elite tennis players. Phys. Ther. Sport 2016, 19, 43-48. [CrossRef]

25. Cejudo, A.; Sainz de Baranda, P.; Ayala, F.; Santonja, F. Test-retest reliability of seven common clinical tests for assessing lower extremity muscle flexibility in futsal and handball players. Phys. Ther. Sport 2015, 16, 107-113. [CrossRef]

26. Almeida, G.P.L.; De Souza, V.L.; Sano, S.S.; Saccol, M.F.; Cohen, M. Comparison of hip rotation range of motion in judo athletes with and without history of low back pain. Man. Ther. 2012, 17, 231-235. [CrossRef] [PubMed]

27. Calatayud, J.; Martin, F.; Gargallo, P.; García-Redondo, J.; Colado, J.C.; Marín, P.J. The validity and reliability of a new instrumented device for measuring ankle dorsiflexion range of motion. Int. J. Sports Phys. Ther. 2015, 10, 197-202. 
28. Holla, J.F.M.; Van Der Leeden, M.; Roorda, L.D.; Bierma-Zeinstra, S.M.A.; Damen, J.; Dekker, J.; Steultjens, M.P.M. Diagnostic accuracy of range of motion measurements in early symptomatic hip and/or knee osteoarthritis. Arthritis Care Res. 2012, 64, 59-65. [CrossRef]

29. Young, W.; Clothier, P.; Otago, L.; Bruce, L.; Liddell, D. Acute effects of static stretching on hip flexor and quadriceps flexibility, range of motion and foot speed in kicking a football. J. Sci. Med. Sport 2004, 7, 23-31. [CrossRef]

30. Roach, S.; San Juan, J.G.; Suprak, D.N.; Lyda, M. Concurrent validity of digital inclinometer and universal goniometer in assessing passive hip mobility in healthy subjects. Int. J. Sports Phys. Ther. 2013, 8, 680-688.

31. L'Hermette, M.; Polle, G.; Tourny-Chollet, C.; Dujardin, F. Hip passive range of motion and frequency of radiographic hip osteoarthritis in former elite handball players. Br. J. Sports Med. 2006, 40, 45-49. [CrossRef]

32. Charlton, P.C.; Raysmith, B.; Wollin, M.; Rice, S.; Purdam, C.; Clark, R.A.; Drew, M.K. Knee flexion strength is significantly reduced following competition in semi-professional Australian Rules football athletes: Implications for injury prevention programs. Phys. Ther. Sport 2018, 31, 9-14. [CrossRef] [PubMed]

33. Bishop, C.; Lake, J.; Loturco, I.; Papadopoulos, K.; Turner, A.; Read, P. Interlimb Asymmetries: The need for an individual approach to data analysis. J. Strength Cond. Res. 2021, 35, 695-701. [CrossRef] [PubMed]

34. Hopkins, W.G.; Marshall, S.W.; Batterham, A.M.; Hanin, J. Progressive statistics for studies in sports medicine and exercise science. Med. Sci. Sports Exerc. 2009, 41, 3-13. [CrossRef]

35. Wollin, M.; Thorborg, K.; Pizzari, T. Monitoring the effect of football match congestion on hamstring strength and lower limb flexibility: Potential for secondary injury prevention? Phys. Ther. Sport 2018, 29, 14-18. [CrossRef] [PubMed]

36. Mujika, I.; Padilla, S. Detraining: Loss of training induced physiological and performance adaptation. Part I. Short term insufficient training stimulus. Sports Med. 2000, 30, 79-87. [CrossRef]

37. Moreno-Pérez, V.; Soler, A.; Ansa, A.; López-Samanes, Á.; Madruga-Parera, M.; Beato, M.; Romero-Rodríguez, D. Acute and chronic effects of competition on ankle dorsiflexion ROM in professional football players. Eur. J. Sport Sci. 2020, 20, 51-60. [CrossRef]

38. López-Valenciano, A.; Ayala, F.; Vera-García, F.J.; de Ste Croix, M.; Hernández-Sánchez, S.; Ruiz-Pérez, I.; Cejudo, A.; Santonja, F Comprehensive profile of hip, knee and ankle ranges of motion in professional football players. J. Sports Med. Phys. Fit. 2019, 59, 102-109. [CrossRef]

39. Seymore, K.D.; Domire, Z.J.; DeVita, P.; Rider, P.M.; Kulas, A.S. The effect of Nordic hamstring strength training on muscle architecture, stiffness, and strength. Eur. J. Appl. Physiol. 2017, 117, 943-953. [CrossRef]

40. Mizrahi, J. Fatique Effect on Running Kinematics. Hum. Mov. Sci. 2000, 19, 139-151. [CrossRef]

41. Fousekis, K.; Tsepis, E.; Vagenas, G. Lower limb strength in professional soccer players: Profile, asymmetry, and training age. J. Sports Sci. Med. 2010, 9, 364-373.

42. Daneshjoo, A.; Rahnama, N.; Mokhtar, A.H.; Yusof, A. Bilateral and unilateral asymmetries of isokinetic strength and flexibility in male young professional soccer players. J. Hum. Kinet. 2013, 36, 45-53. [CrossRef] [PubMed]

43. Oshita, K.; Yano, S. Asymmetry of Force Fluctuation During Low Intensity Isometric Contraction in Leg Muscle. Int. J. Exerc. Sci. 2010, 3, 68-77. [PubMed]

44. Hölmich, P.; Uhrskou, P.; Ulnits, L.; Kanstrup, I.L.; Bachmann Nielsen, M.; Bjerg, A.M.; Krogsgaarda, K. Effectiveness of active physical training as treatment for long-standing adductor-related groin pain in athletes: Randomised trial. Lancet 1999, 353, 439-443. [CrossRef]

45. Bourne, M.N.; Timmins, R.G.; Opar, D.A.; Pizzari, T.; Ruddy, J.D.; Sims, C.; Williams, M.D.; Shield, A.J. An Evidence-Based Framework for Strengthening Exercises to Prevent Hamstring Injury. Sports Med. 2018, 48, 251-267. [CrossRef] 